\title{
Três espécies novas de Gaesischia Michener, LaBerge \& Moure e notas sobre Gaesischia melanaspis Urban (Hymenoptera, Apidae) ${ }^{1}$
}

\author{
Danúncia Urban ${ }^{2}$ \\ ${ }^{1}$ Contribuição número 1683 do Departamento de Zoologia, Universidade Federal do Paraná. \\ ${ }^{2}$ Departamento de Zoologia, Universidade Federal do Paraná. Caixa Postal 19020, 81531-980 Curitiba, Paraná, Brasil. \\ Bolsista do CNPq. E-mail: urban@ufpr.br
}

\begin{abstract}
Three new species of Gaesischia Michener, LaBerge \& Moure and notes about Gaesischia melanaspis Urban (Hymenoptera, Apidae). Gaesischia caracicola sp. nov., Gaesischia cipoana sp. nov. and Gaesischia horizontina sp. nov., from Minas Gerais, are described and illustrated.Variations of the integument and the pilosity of Gaesischia melanaspis Urban, 1968, are presented.
\end{abstract}

KEYWORDS. Eucerini; neotropical; taxonomy.

RESUMO. Três espécies novas de Gaesischia Michener, Laberge \& Moure e notas sobre Gaesischia melanaspis Urban (Hymenoptera, Apidae). Gaesischia caracicola sp. nov., Gaesischia cipoana sp. nov. e Gaesischia horizontina sp. nov., de Minas Gerais, são descritas e ilustradas. São dadas notas sobre as variações do tegumento e da pilosidade de Gaesischia melanaspis Urban, 1968.

PALAVRAS-CHAVE. Eucerini; Neotropical; taxonomia.

As descrições das espécies de Gaesischia Michener, LaBerge \& Moure, 1955, apresentadas neste trabalho, seguem o padrão usado por Urban $(1968,1989)$. Todas as medidas são em milímetros; as das asas anteriores foram obtidas a partir do ápice do esclerito costal. O material-tipo está depositado nas Coleções Taxonômicas do Instituto de Ciências Biológicas, UFMG, Belo Horizonte (DZMG).

\section{Gaesischia caracicola sp. nov.}

Figs 1-2

Diagnose. Macho com o clípeo esbranquiçado, porém com orla preta junto à sutura epistomal; antenas com franja do segundo ao nono flagelômero; espinhos coxais anteriores longos; palpos maxilares com quatro artículos; tergos com a pilosidade predominantemente branca e esparsa, os três basais com pêlos castanhos finos e esparsos distribuídos numa faixa marginal com forma de arco rebaixado, a faixa do primeiro tergo maior que as dos tergos dois e três.

Holótipo macho. Comprimento aproximado 7,84; asa anterior danificada; largura da cabeça 3,82; comprimento do olho 2,06; distância interorbital superior 2,35 e a inferior 1,91; comprimento máximo do segundo flagelômero 0,98 e do terceiro 0,81 . Cor predominante preta, menos a parte discal do labro e quase todo o clípeo esbranquiçados, o labro enegrecido nos lados; o clípeo com orla preta acompanhando a sutura epistomal e a margem translúcida amarelo-esbranquiçada; antenas com escapo e pedicelo pretos, o flagelo castanho- ferrugíneo; tégulas enegrecidas; asas transparentes com as veias castanho-escuras. Tergos e esternos com faixa marginal translúcida castanho-amarelada, transparente e fracamente esbranquiçada na borda.

Pilosidade: branca na cabeça exceto no vértice onde os pêlos são enegrecidos; no mesoscuto e escutelo enegrecida e rodeada estreitamente com pêlos brancos; nos mesepisternos e pernas branca, amarelo-acastanhada na face ventral dos tarsos; predominantemente branca nos tergos, não densa, os três basais com pêlos castanhos finos e esparsos em uma larga faixa marginal com o contorno anterior em arco rebaixado, esta faixa diminui gradativamente do tergo basal para os seguintes, no terceiro somente no terço dorsal; do terceiro ao quinto tergo com cerdas castanhas e esbranquiçadas no meio da pilosidade, semi-eretas e longas; no tergo distal castanho-pálida e nos esternos esbranquiçada.

Antenas com franja de cerdas decumbentes ao longo do segundo ao nono flagelômero e uma carena fraca acompanhando a franja; palpos maxilares com quatro artículos; coxas anteriores com espinho apical mais longo que os trocanteres; fêmures anteriores polidos, com o bordo posterior em arco rebaixado, sem carena posterior, porém com a franja mais longa na base e não ultrapassando a largura dos fêmures; trocanteres posteriores com carena arqueada e pilosidade curta; fêmures posteriores polidos e com carena posterior, os basitarsos posteriores longos e estreitos, a largura quase igualando $1 / 4$ do seu comprimento e a ponta projetada posteriormente em forma de 
lóbulo, ultrapassando a base do tarsômero adjacente; sexto esterno com duas carenas laminadas paralelas às margens laterais do esterno porém não unidas apicalmente, sem tufo mediano.

Holótipo macho. "Abelhas da Zona/Metalúrgica/S. [Serra] do Caraça/7264-21517"; "Catas Altas MG/Brasil 22/01/2001/ F. A. Silveira" (DZMG).

Comentário. Pela chave de Urban (1989) sai com a $G$. flavoclypeata Michener, LaBerge \& Moure, 1955, que também ocorre em Minas Gerais porém difere de G. caracicola sp. nov. por ter faixa amarela pilosa densa na margem do segundo tergo, os tergos seguintes inteiramente revestidos com pêlos amarelos, mais longos e densos na faixa marginal e misturados com cerdas enegrecidas.

Etimologia. Habitante do Caraça.

\section{Gaesischia cipoana sp. nov.}

\section{Figs 3-4}

Diagnose. Macho com o labro esbranquiçado, clípeo com faixa subapical amarela, um pouco alargada nos cantos; basitarsos posteriores amarelo-ferrugíneos, largos e achatados, mais estreitos junto às articulações; palpos maxilares com cinco artículos.

Holótipo macho. Comprimento aproximado 6,86; comprimento da asa anterior 5,73; largura da cabeça 3,57; comprimento do olho 2,10; distância interorbital superior 2,10 e a inferior 1,86; comprimento máximo do segundo flagelômero 1,13 e do terceiro 0,94 . Cor predominante preta, menos o labro esbranquiçado e o clípeo com uma faixa subapical amarela, um pouco alargada nos flancos e a margem translúcida mélea; flagelo castanho-amarelado ventralmente e castanho na face dorsal, menos o último artículo inteiramente preto e o primeiro todo castanho; tégulas pretas; asas tingidas fracamente de enegrecido, veias pretas; pernas com os dois artículos basais pretos e os demais amarelo-ferrugíneos, nas anteriores o preto também na parte externa dos fêmures; nas medianas e posteriores a área preta ocupando grande parte dos fêmures, limitando o amareloferrugíneo a uma pequena área na face ventral. Tergos e esternos com faixa marginal translúcida larga acastanhada e a borda transparente e um pouco amarelada.

Pilosidade: branca na cabeça, com mescla de pêlos de cor creme e pretos no vértice; preta na metade posterior do disco do mesoscuto, a área preto-pilosa alargando para a base e rodeada de pêlos creme nos lados e anteriormente, e pêlos brancos no ápice; preta em quase todo o escutelo, com pêlos de cor creme misturados aos pretos junto ao metanoto; branca nos mesepisternos e pernas, com mescla de cerdas enegrecidas na face externa das tíbias posteriores; branca e longa na maior parte do tergo basal, com faixa marginal larga de pêlos pretos curtos, lisos e decumbentes, até os flancos; do segundo ao quinto tergo com faixa basal de pêlos brancos curtos e denso-plumosos e a faixa marginal como a do primeiro tergo porém variando na largura; no segundo tergo a faixa marginal com o dobro da largura da faixa do tergo anterior e só um pouco estreitada nos lados, reduzindo a faixa basal a uma estria fina dorsal, um pouco alargada nos flancos; no terceiro, a faixa ocupando a metade distal do tergo, angulosa no meio e muito curta nos flancos; nos dois seguintes diminuindo gradativamente; sexto tergo com pêlos brancos alongados e decumbentes, denso-plumosos e o distal com pêlos enegrecidos. Do quarto ao sexto tergo com cerdas enegrecidas entre a pilosidade. Esternos com franjas brancas semi-decumbentes.

Antenas com duas carenas fracas na face dorsal do primeiro ao nono flagelômero, sem franja cerdosa; palpos maxilares com cinco artículos; coxas anteriores com espinho apical curto, arredondado e pouco maior que o ocelo mediano; fêmures anteriores com o bordo posterior em arco rebaixado, sem carena, com a face anterior em parte polida e em parte micro-reticulada, a pilosidade curta na base e um pouco alongada para o ápice; trocanteres posteriores com a pilosidade curtíssima e carena angulosa ao longo do comprimento; fêmures posteriores carenados, com a face ventral quase fosca até o meio; basitarsos posteriores achatados, com os lados paralelos e mais largos que 1/3 do seu comprimento, porém mais estreitos junto às articulações, com uma depressão na face externa e, a ponta não ultrapassando a base do tarsômero adjacente; sexto esterno com carenas laterais laminadas paralelas aos bordos, unidas subapicalmente de forma bilobada, os lobos com o contorno laminado para trás e não para baixo como as carenas laterais; a área entre as carenas laterais com rúgulas muito finas e numerosas, paralelas às carenas laterais e convergentes para o meio do esterno.

Holótipo macho. "S. [Serra] do Cipó/8645-26237"; " Santana do Riacho MG/Brasil 08/10/2003/A. A. Azevedo", (DZMG).

Comentário. Na chave de URBAN (1989) sai com a Gaesischia carinata Urban, 1989, descrita da Bahia, pelas numerosas rúgulas do sexto esterno, paralelas e convergentes para o meio do esterno. G. carinata difere pelo clípeo quase inteiramente amarelo, ausência de espinho coxal anterior, pela forma dos basitarsos posteriores, muito estreitos na metade basal e com o dobro da largura na distal e, por ter somente cerdas brancas na face externa das tíbias posteriores.

\section{Gaesischia horizontina sp. nov.}

\section{Figs 5-6}

Diagnose. Macho com mácula subapical esbranquiçada no clípeo, alargando para o meio; pilosidade predominante amarelo-fulva, porém com pêlos enegrecidos nos três tergos distais; quatro artículos nos palpos maxilares.

Holótipo macho. Comprimento aproximado 9,21; comprimento da asa anterior 6,95; largura da cabeça 3,43; comprimento do olho 1,91; distância interorbital superior 2,06 e a inferior 1,76; comprimento máximo do segundo flagelômero 0,84 e do terceiro 0,67 . Cor geral preta, menos a mácula clipeal esbranquiçada, subapical, angulosa para o meio do clípeo e não chegando aos flancos; a face ventral do flagelo amareloferrugínea e a dorsal castanha, somente a metade apical do úl- 

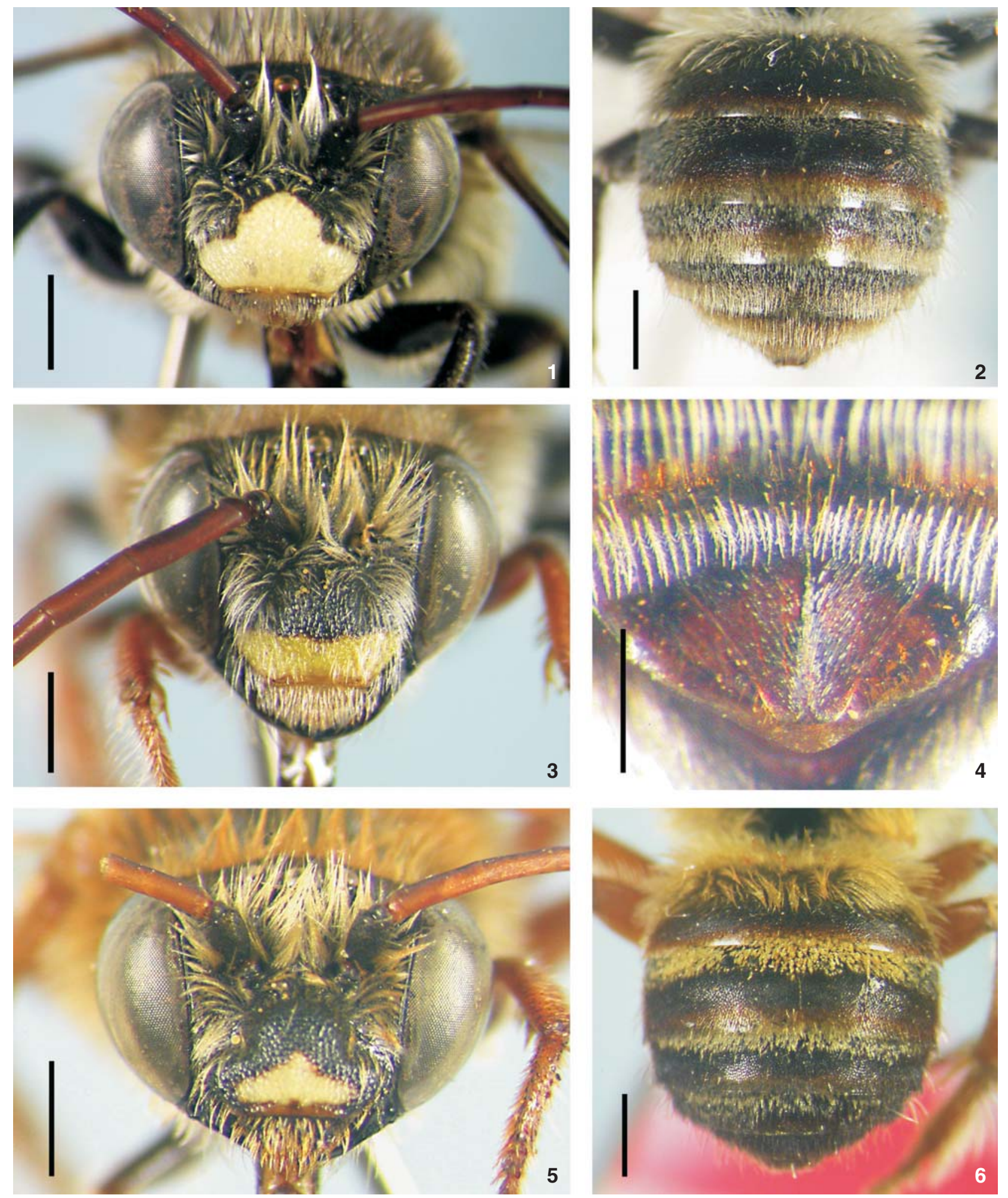

Figuras 1-6. Holótipos machos: (1-2) Gaesischia caracicola sp. nov., cabeça e metassoma; (3-4) Gaesischia cipoana sp. nov., cabeça e esternos distais; (5-6) Gaesischia horizontina sp. nov., cabeça e metassoma. Escalas de $1 \mathrm{~mm}$, exceto na figura 4 com escala de 0,5 mm.

Revista Brasileira de Zoologia 24 (2): 470-473, junho 2007 
timo flagelômero preta; tégulas translúcidas amareloferrugíneas; asas tingidas de amarelo-méleo, veias méleas; pernas em grande parte amarelo-ferrugíneas; tergos com margem translúcida castanho-amarelada, passando para amarelada na borda dos três basais, nos demais a borda translúcida mais estreita e enegrecida; esternos pretos na base, castanho-amarelados no disco e com a margem fina transparente.

Pilosidade: creme na face, genas, pernas e mesepisternos; amarelo-fulva no vértice, dorso do mesossoma e na metade basal do primeiro tergo; a faixa marginal do primeiro tergo com pêlos pretos finos, curtos e decumbentes; segundo e terceiro tergos com faixa basal de pêlos curtos denso-plumosos amarelados e nos $2 / 3$ distas com pêlos pretos muito curtos e semidecumbentes; quarto tergo com pilosidade basal esbranquiçada, curta e denso-plumosa e faixa marginal, angulosa medialmente, revestida de pêlos bem pequenos e pretos; enegrecida nos três tergos distais; terceiro ao quinto tergo com cerdas enegrecidas de permeio com a pilosidade, as cerdas mais longas que os pêlos; amarelada nos esternos.

Antenas sem franja cerdosa, com duas carenas fracas ao longo do primeiro até o nono flagelômero, os distais não alargados; palpos maxilares com quatro artículos; coxas anteriores com espinho apical curto; fêmures anteriores com a face posterior em arco rebaixado, brilhante e sem carena, a pilosidade quase tão longa quanto a largura do fêmur; trocanteres posteriores sem carena e com a pilosidade muito curta; fêmures posteriores polidos, com carena ao longo do comprimento; basitarsos posteriores estreitos, porém um pouco mais largos para o ápice, aí medindo cerca de $1 / 4$ do seu comprimento, sem tufo piloso na face externa e sem depressão mediana; sexto esterno com depressão mediana delgada, carenas laminadas paralelas aos bordos laterais unidas distalmente por uma carena muito fina em arco.

Holótipo macho. "Abelhas da Zona/Metalúrgica MG/ Campus UFMG/1143-2948”; Belo Horizonte MG/Brasil 23/04/ 1997/J. C. Moreira", (DZMG).

Comentário. Na chave de Urban (1989) sai juntamente com G. belophora (Moure, 1941) que tem pilosidade amarela e densa do segundo ao quarto tergo e faixa discal preto-pilosa, às vezes ausente no terceiro tergo.

\section{Gaesischia melanaspis Urban, 1968}

Gaesischia melanaspis Urban, 1968: 105.

Espécie conhecida anteriormente de Bauru, São Paulo. Pela primeira vez foram examinados espécimes coletados em Minas Gerais. Nestes, foi observada variação no colorido da pilosidade e também no tegumento do clípeo. O holótipo macho tem o clípeo preto e, a pilosidade creme na cabeça, em grande parte dos mesepisternos e nos artículos basais das pernas; amareloarruivada no dorso do mesossoma, lobos pronotais, áreas adjacentes dos mesepisternos e no tergo basal.

Dentre os machos coletados em Minas Gerais, foram vistos somente dois com o mesmo padrão do holótipo, sendo um de Sabará, coletado por R. B. Martines e outro de Sta. Bárbara, por A. F. Kumagai; outros dois machos com a pilosidade idêntica à do holótipo, porém com o clípeo ornado com faixa amarela subapical, sendo um de Belo Horizonte, coletado por D. A. Yanega e o outro de São Gonçalo do Rio Abaixo, coletado por N. G. Fonseca. Desta última localidade, foram examinados mais dois machos obtidos na mesma coleta, com a pilosidade preta na metade ventral da cabeça, nas pernas e em quase todo o mesossoma, acastanhada no propódeo e na face ventral dos mesepisternos, com pêlos de cor creme somente na fronte. Um macho de Belo Horizonte, coletado por G. Sousa, com pilosidade castanho-dourada no dorso do mesossoma e preta nos mesepisternos.

\section{AGRADECIMENTOS}

A Albino M. Sakakibara e Antonio J.C. Aguiar, Departamento de Zoologia, UFPR, pelas fotos que ilustram o trabalho e a Fernando A. Silveira, Departamento de Zoologia, UFMG, pelo empréstimo dos espécimes para o estudo.

\section{REFERÊNCIAS BIBLIOGRÁFICAS}

Urban, D. 1968. As espécies de Gaesischia Michener, LaBerge \& Moure, 1955 (Hymenoptera, Apoidea). Boletim da Universidade Federal do Paraná, Zoologia III (4): 79-129.

Urban, D. 1989. Espécies novas e notas sobre o gênero Gaesischia Michener, LaBerge \& Moure, 1955 (Hymenoptera, Apoidea). Revista Brasileira de Entomologia 33 (1): 75-102.

Recebido em 20.III.2007; aceito em 04.VI.2007. 